\title{
Cytarabine-Daunorubicin Regimen
}

National Cancer Institute

\section{Source}

National Cancer Institute. Cytarabine-Daunorubicin Regimen. NCI Thesaurus. Code C63602.

A regimen consisting of cytarabine and daunorubicin used as both as induction and consolidation (post remission) treatment for acute myeloid leukemia. 